\title{
A partial skeleton of a new lamniform mackerel shark from the Miocene of Europe
}

Jürgen Kriwet, Heike Mewis, and Oliver Hampe

Acta Palaeontologica Polonica 60 (4), 2015: 857-875 doi:http://dx.doi.org/10.4202/app.00066.2014

Cenozoic lamniform sharks are mostly represented by isolated teeth and vertebrae, whereas articulated skeletal remains are usually very scarce. Here, we describe a partial skeleton of an extinct lamniform shark consisting of 42 slightly disarticulated teeth, 49 vertebrae, and additional unidentifiable cranial and postcranial remains. The specimen originates from the Miocene mica-clay of Groß Pampau (North Germany), which is of late Langenfeldian age (= Serravallian-Tortonian boundary; middle-late Miocene). A total of 13 measurements of each tooth, as well as morphological features, were used to reconstruct the dentition of this specimen and to provide detailed taxonomic information. Additionally, the total body size and age at death were established using methodologies based on vertebral and tooth measurements and vertebral centra growth ring counts, respectively. The specimen undoubtedly represents the most complete individual of "Carcharodon (= Isurus) escheri", previously known only from a few isolated teeth. The dental pattern (e.g., marked dignathic and monognathic heterodonty patterns; only slightly labio-lingually compressed upper teeth; upper teeth slender with distally inclined or curved main cusps; massive, hook-like upper intermediate tooth; main cusps with crenulated cutting edges; lateral cusplets in teeth of all ontogenetic stages) clearly separates this shark from all hitherto known Cenozoic and Recent lamnids and a new genus, Carcharomodus, consequently is introduced. Carcharomodus escheri comb. nov. is a characteristic element of late early Miocene to the Pliocene Western and Central European fish faunas. All previously identified Pacific occurrences represent a different taxon. We estimate that the specimen had a total body length of about $4 \mathrm{~m}$ and that it was older than 10 years and thus might have reached maturity before death, as indicated by all available evidence.

Key words: Chondrichthyes, Lamniformes, Lamnidae, Carcharomodus, postcranium, Miocene, Langenfeldian, Germany.

Jürgen Kriwet [juergen.kriwet@univie.ac.at], Department of Palaeontology, University of Vienna, Geozentrum, Althanstr. 14, A-1090 Vienna, Austria; Heike Mewis [heike.mewis@gmail.com] and Oliver Hampe [oliver.hampe@ mfn-berlin.de], Museum für Naturkunde, Leibniz Institute for Research on Evolution and Biodiversity, Invalidenstr. 43, D-10115 
Berlin, Germany.

This is an open-access article distributed under the terms of the Creative Commons Attribution License (for details please see creativecommons.org), which permits unrestricted use, distribution, and reproduction in any medium, provided the original author and source are credited.

FoF 